\title{
Comparison of caregivers' characteristics, stigma, and disease burden of children with autism spectrum disorder and attention- deficit disorder in Egypt
}

\author{
Romany H. Gabra ${ }^{*}$ (1) and Doaa F. Hashem²
}

\begin{abstract}
Background: Studies show that autism spectrum disorder and attention-deficit hyperactivity disorder place a significant stigma and burden on caregivers, economically as well as socially, psychologically, and emotionally. The current study aims to assess caregivers of those children with reference to stigma and disease burden, evaluation of different psychiatric symptoms, and quality of life. Also, it aims to compare the extent of such disruption related to the type of the disorder (ASD versus ADHD). A cross-sectional, analytical study was designed including 72 caregivers $\{38$ caregivers of autism versus 34 caregivers of ADHD\}; all of them were assessed for (1) stigma; (2) disease burden; (3) depression, anxiety, and sensitivity; and (4) quality of life.
\end{abstract}

Results: The current results show that caregivers of ASD and ADHD have a higher score of stigmas, burden, depression, anxiety, and a poorer QoL than normal; all these variables are worse in ASD caregivers than ADHD caregivers.

Conclusion: This study supports the notion that both ADHD and ASD pose a great challenge for their caregivers which is higher in ASD than ADHD caregivers.

Keywords: Autism spectrum disorder, ASD, Attention-deficit hyperactivity disorder, ADHD, Stigma, Burden, Quality of life, Depression, Anxiety

\section{Background}

Autism spectrum disorder (ASD) is a neurodevelopmental disorder with increasing morbidity in recent years. Children diagnosed with ASD often have deficits in social functioning, exhibit repetitive, stereotyped, and selfstimulatory behavior and typically show marked delay in the development of verbal language [1]. Attention-deficit/hyperactivity disorder (ADHD) is a neurobehavioral disorder characterized by inattention, impulsivity, and hyperactivity [1]. Both ASD and ADHD have heterogeneous and variable impacts on functioning and daily

\footnotetext{
*Correspondence: romanyhosny@med.aun.edu.eg

${ }^{1}$ Department of Neurology and Psychiatry, Faculty of Medicine, Assiut University, Assiut, Egypt

Full list of author information is available at the end of the article
}

activities for these children and their caregivers. Both disorders need multidisciplinary management involving educational, psychological, and behavioral interventions and pharmacological treatment is recommended by most European guidelines [2, 3].

Parents of children with developmental disabilities face challenges that place them at high risk of distress and negative psychological outcomes. Parenting a child with autism and ADHD involves additional stressors related to the child's challenges in communication, unpredictable and aggressive behaviors, limitations in self-care, and lack of respite owing to an inability to find suitable substitute caregivers. There is growing awareness regarding caregiver stigma and burden for families raising children and adolescents with autism 
spectrum disorders (ASDs) and ADHD. In this issue, Cadman et al. [4] focus on the increased recognition that both ASD and attention-deficit/hyperactivity disorder (ADHD) are associated with significant mental and emotional burdens to caregivers. However, the extent of caregiver suffering is clearly different in both disorders [5].

There are a limited studies that focus on caregivers of these children in Egypt. Most of the current research focuses mainly on autistic disorder with limited studies that considered the caregivers of ADHD children. Moreover, there is almost no previous work comparing the extent of stigma and caregiver burden of caregivers in both disorders. Affiliate stigma in caregivers of ASD and ADHD children can affect caregivers' psychological health. It describes the process of internalizing, and coming to be believe, criticism from others that negatively impacts the mental health of those vulnerable caregivers [6].

People with high affiliate stigma may develop negative self-evaluation and have high level of negative emotions; they become withdrawn and tend to conceal their stigmatized soul from others which add to more isolation of such people and their affected children [7]. The lived experience of stigma among caregivers of children with ASD and ADHD has been the topic of much qualitative research. Results suggest caregivers' experience of stigma, which manifest as hostile stares, insensitive comments, and social exclusion, to be underpinned by lack of knowledge about ASD and ADHD. Across several studies, caregivers comment that schools, even family, and close friends did not know enough about ASD and ADHD. Caregivers perceived this as ultimately leading to stigma, characterized by feeling judged, disliked, rejected, and receiving inadequate support [8].

The quality of life of caregivers can be affected by the disease symptoms. Thus, parents of children with ASD or ADHD are more likely to develop psychological, social, and physical problems than parents of asymptomatic children in addition to being influenced by these symptoms because of their children's illness [9].

\section{Study objectives}

The current study is a cross-sectional, analytical one aiming to assess some psychiatric characteristics (depression, anxiety, sensitivity) of the caregivers of children with ASD and ADHD. Also, it aims to assess the level of stigma and disease burden and its impact on the quality of life of those caregivers; also, we aimed to compare those data between caregivers of both disorders.

\section{Methods}

\section{Participants}

The current study includes 72 caregivers $\{38$ Caregivers of Autism versus 34 Caregivers of ADHD\}. All of them were recruited from two centers: the first is Assiut University's psychological and educational counseling center, and the second is from child and adolescent outpatient clinic in Neurology and psychiatry department, Assiut University Hospital. The current study were performed from 1 January 2021 up to 1 May 2021; availability sample was used as all the patients coming to both centers were interviewed during this duration and those who accept to participate were included. Parents were chosen randomly from both centers after their children met the diagnostic criteria of ASD and ADHD according to DSM5. Parents of children who have mental retardation or other sever psychiatric disorders (except ASD and ADHD) were excluded from the study.

Eligible participants were then given a description of the study and asked for their acceptance to take part. Following the requirement of written informed consent, participants were asked to complete a comprehensive questionnaire to collect demographic information, followed by a clinical interview with doctors to assess their psychological problems and other scales.

\section{Study tools}

1- Clinical and demographic data of ASD and ADHD children and their caregivers: such as gender of child, age of child, the severity of the disease, and duration of the disease. Caregivers were assessed regarding age, sex, education, and occupational status.

2- The Arabic Version of the Zarit Burden Interview (ZBI) $[10,11]$ is a 22 -item self-report scale which measures the burden of the specified behavior and level of functioning of the caregivers in respect to interpersonal relations, financial affairs, physical health, and social life. In the current study, the reliability and the validity of Burden Interview symptom checklist were assessed in a sample of the study $(n=45)$ by using Cronbach's Alpha coefficient. Cronbach's Alpha coefficient value was 0.74 while for the validity by using validity convergent with depression scale, the correlation coefficient was $P=0.45^{* * *}$.

3- Explanatory Model Interview Catalogue-Community Stigma Scale (EMIC-CSS) [12]: this scale assesses the attitudes and behavior of the stigmatized persons in 15 items. The EMIC-CSS addresses several aspects of life that may be impacted by stigma, such 
as avoidance, concealment, shame, pity, being made fun of respect, and marriage (prospects). In the current study, the reliability and the validity stigma scale for caregivers of people with mental illness (CPMI) was assessed in a sample of the study $(n=45)$ by using Cronbach's alpha coefficient. Cronbach's alpha coefficient value was 0.74 while the validity by using validity convergent with depression scale was $p=0.34^{*}$.

4- Symptom Checklist 90 "SCL 90" [13]: SCL is a 90-item questionnaire that is used to assess different mental health issues. Each item of these is rated on a scale of 0 to 4 based on the degree of being problematic to the individual. It is divided into nine subscales but the current study uses only three subscales such as depression, anxiety, and interpersonal sensitivity.

5- The World Health Organization Quality of Life-BREF (WHOQOL-BREF). It is used to assess the individual subjective perceptions of quality of life [14]. The WHOQOL-BREF includes four domains of QOL: Physical Capacity (7 items), Psychological Well-being (6 items), Social Relationship (4 items), and Environment (9 items). Each item is scored on a 5-point Likert scale, with higher scores indicating better QOL. In the current study the reliability and the validity of Quality of life was assessed in a sample of the study $(n=45)$ by using Cronbach's alpha coefficient. Cronbach's alpha coefficient value was 0.76 , while the validity by using validity convergent with depression scale was $P=-0.31^{*}$.

\section{Statistical analysis}

In this study, SPSS has been used for statistical analysis (version 26). Different descriptive statistics, frequencies, and percentages were presented. Assessment of categorical variables was done by the Pearson chi-squared test. The evaluation of quantitative variables was conducted with an independent $t$-test to detect if there is any significant difference in means between any two groups. To identify risk factors, multivariate linear regression model was done. Statistically significant was the probability value ( $p$-value) of $<0.05$.

\section{Ethics approval and consent to participate}

Before starting data collection, approvals to conduct the study were obtained from the Ethical Review Committee of Assiut Faculty of Medicine and the administrative authority in Neurological and Psychiatric Hospital at Assiut University. Prior to the interview, written informed consent was obtained. Privacy and secrecy of all data were assured by ensuring the anonymity of the questionnaire, interviewing the participants separately in a closed room and keeping data files in a safe place.

\section{Results}

The current study includes 72 caregivers of ASD and ADHD children (38 caregivers of autism versus 34 caregivers of ADHD) recruited from Assiut governorate (Assiut University's psychological and educational counseling center, and from child and adolescent outpatient clinic in Neurology and psychiatry department, Assiut University Hospital) caregivers of autistic children were 17 father and 21 mother caregivers, while caregivers of ADHD children were 13 fathers and 21 mothers. The age range of the studied sample was from 24 to 45 years old. The average education years of caregivers of autism were 13.41 years, while the average education years of ADHD caregivers were 12.85 years (Table 1 ).

Assessment of depression, anxiety, and sensitivity symptoms of the caregivers using SCL 90 shows that $37.5 \%$ of the caregivers show depressive symptoms, $25 \%$ of the caregivers show anxiety symptoms, and 13.9\% of the caregivers show abnormal sensitivity symptoms (Table 1).

Comparison of affiliate stigma and associative stigma between caregivers shows that the mean affiliate stigma of ASD caregivers was $45.86 \pm 11.45$ compared to $40.44 \pm$ 8.12 of ADHD caregivers. The mean associative stigma of ASD caregivers was $18.0789 \pm 8.07$ compared to $11.41 \pm 4.39$ of ADHD caregivers; both were of statistical significance indicating that both types of stigmas are higher in caregivers of autism than those with ADHD (Table 2 and Fig. 1).

Assessment of disease burden shows that caregivers of autism have mean score $42.10 \pm 11.62$ while caregivers of ADHD have mean score of $34.20 \pm 16.68$ which was also of statistical significance. This indicates that disease burden is much higher in caregivers of autism than ADHD (Table 2 and Fig. 1).

Evaluation of depressive symptoms shows that caregivers of autistic children have higher scores of depression, anxiety, and sensitivity than those caregivers of ADHD children $(1.60 \pm .80,1.28 \pm .72,1.50 \pm .79$ versus $1.25 \pm .51$, $.92 \pm .47,1.01 \pm .48$ respectively) which were of statistical significance (Table 2 and Fig. 1).

Evaluating the quality of life, the caregivers show that there is a significantly lower quality of life in caregivers of autism than those with ADHD (59.84 \pm 14.08 versus $70.05 \pm 13.04$ respectively) (Table 2 and Fig. 1).

Comparison of affiliate stigma and associative stigma, burden scale, and sensitivity, between father caregivers and mother caregivers of both disorders, shows that mothers of these children have statistically significant higher scores of stigmas, burden, and sensitivity than father caregivers while there was no difference in scores of depressions and anxiety symptoms between father and mother caregivers (Table 3 and Fig. 2). 
Table 1 Demographic and psychological characteristics of the sample study

\begin{tabular}{|c|c|c|c|c|c|c|c|c|c|c|c|}
\hline \multirow[t]{3}{*}{ Variables } & & \multicolumn{4}{|c|}{ Caregivers of autism $(N=38)$} & \multicolumn{4}{|c|}{ Caregivers of ADHD $(N=34)$} & \multirow{2}{*}{\multicolumn{2}{|c|}{$\begin{array}{l}\text { Total }(N= \\
72)\end{array}$}} \\
\hline & & \multicolumn{2}{|c|}{$\begin{array}{l}\text { Father caregivers of } \\
\text { autism }(N=17) \\
\end{array}$} & \multicolumn{2}{|c|}{$\begin{array}{l}\text { Mother caregivers of } \\
\text { autism }(N=21)\end{array}$} & \multicolumn{2}{|c|}{$\begin{array}{l}\text { Father caregivers of } \\
\text { ADHD }(N=13)\end{array}$} & \multicolumn{2}{|c|}{$\begin{array}{l}\text { Mother caregivers of } \\
\text { ADHD }(N=21)\end{array}$} & & \\
\hline & & $N$ & $\%$ & $N$ & $\%$ & $N$ & $\%$ & $N$ & $\%$ & $N$ & $\%$ \\
\hline \multirow[t]{3}{*}{ Age } & 24-34 years & 8 & 11.1 & 12 & 16.7 & 5 & 6.9 & 11 & 15.3 & 36 & 50 \\
\hline & $35-45$ years & 9 & 12.5 & 9 & 12.5 & 8 & 11.1 & 10 & 13.9 & 36 & 50 \\
\hline & Mean \pm SD & $34.35 \pm 2.44$ & & $35.62 \pm 3.11$ & & $34.15 \pm 5.90$ & & $33.57 \pm 5.13$ & & - & \\
\hline \multirow{5}{*}{$\begin{array}{l}\text { Numbers of years } \\
\text { of education }\end{array}$} & 8 years & 1 & 1.4 & 0 & 0 & 1 & 1.4 & 3 & 4.2 & 5 & 6.9 \\
\hline & 11 years & 7 & 9.7 & 8 & 11.1 & 5 & 6.9 & 8 & 11.1 & 28 & 38.9 \\
\hline & 15 years & 7 & 9.7 & 10 & 13.9 & 5 & 6.9 & 10 & 13.9 & 32 & 44.4 \\
\hline & 17 years & 2 & 2.8 & 3 & 4.2 & 2 & 2.8 & 0 & 0 & 7 & 9.7 \\
\hline & Mean \pm SD & $13.17 \pm 2.65$ & & $13.66 \pm 2.22$ & & $13.23 \pm 2.83$ & & $12.47 \pm 2.65$ & & - & \\
\hline \multirow[t]{2}{*}{ Work } & Work & 15 & 20.8 & 8 & 11.1 & 12 & 16.7 & 8 & 11.1 & 43 & 59.7 \\
\hline & No work & 2 & 2.8 & 13 & 18.1 & 1 & 1.4 & 13 & 18.1 & 29 & 40.3 \\
\hline \multirow[t]{2}{*}{ Depression } & Normal & 10 & 13.9 & 9 & 12.5 & 8 & 11.1 & 18 & 25 & 45 & 62.5 \\
\hline & Abnormal & 7 & 9.7 & 12 & 16.7 & 5 & 6.9 & 3 & 4.2 & 27 & 37.5 \\
\hline \multirow[t]{2}{*}{ Anxiety } & Normal & 11 & 15.3 & 11 & 15.3 & 13 & 18.1 & 19 & 26.4 & 54 & 75 \\
\hline & Abnormal & 6 & 8.3 & 10 & 13.9 & 0 & 0 & 2 & 2.8 & 18 & 25 \\
\hline \multirow[t]{2}{*}{ Sensitivity } & Normal & 16 & 22.2 & 14 & 19.4 & 12 & 16.7 & 20 & 27.8 & 62 & 86.1 \\
\hline & Abnormal & 1 & 1.4 & 7 & 9.7 & 1 & 1.4 & 1 & 1.4 & 10 & 13.9 \\
\hline
\end{tabular}

$A D H D$ attention-deficit hyperactivity disorder

Table 2 Comparison of affiliate stigma and associative stigma, burden scale, and anxiety, sensitivity, and quality of life between caregivers of autism and caregivers of ADHD

\begin{tabular}{lllll}
\hline Variables & $\begin{array}{l}\text { Caregivers } \\
\text { of autism }(\boldsymbol{N} \\
=\mathbf{3 8}) \\
\text { Mean } \pm \text { SD }\end{array}$ & $\begin{array}{l}\text { Caregivers } \\
\text { of ADHD }(\boldsymbol{N} \\
=\mathbf{3 4})\end{array}$ & $\begin{array}{l}\boldsymbol{T} \\
\text { Mean } \pm \text { SD }\end{array}$ & $\boldsymbol{p}$ value \\
\hline Affiliate stigma & $45.86 \pm 11.45$ & $40.44 \pm 8.12$ & 2.33 & .022 \\
Associative stigma & $18.0789 \pm 8.07$ & $11.41 \pm 4.39$ & 4.40 & .000 \\
Burden scale & $42.10 \pm 11.62$ & $34.20 \pm 16.68$ & 2.30 & .009 \\
Depression & $1.60 \pm .80$ & $1.25 \pm .51$ & 2.217 & .030 \\
Anxiety & $1.28 \pm .72$ & $.92 \pm .47$ & 2.569 & .013 \\
Sensitivity & $1.50 \pm .79$ & $1.01 \pm .48$ & 3.163 & .002 \\
Quality of life & $59.84 \pm 14.08$ & $70.05 \pm 13.04$ & 3.181 & .002 \\
\hline
\end{tabular}

$A D H D$ attention-deficit hyperactivity disorder

Correlation between affiliate stigma with depression, anxiety, sensitivity, and quality of life shows that there is a significant positive correlation between affiliate stigma with depression, anxiety, and sensitivity. Also, it shows a significantly negative correlation between affiliate stigma with quality of life of those caregivers (Table 4).

Results of a simple regression analysis of affiliate stigma in predicting depression, anxiety, sensitivity, and quality of life in caregivers of ADHD and ASD children show that affiliate stigma has a statistically significant predictive power for the development of depression, anxiety, and sensitivity with negative impact for the QOL (Table 5).

\section{Discussion}

The current study is a descriptive analytical one examining the impact of affiliate and associative stigmas and disease burden on some aspects of mental health and QOL of the caregivers of children with ASD and ADHD. Also, it provides a chance to compare the differences of stigma and disease burden between caregivers of ASD versus caregivers of ADHA and its possible impact on depression, anxiety, and sensitivity of them.

The current study includes 72 caregivers of ASD and ADHD children (38 caregivers of autism versus 34 caregivers of ADHD) includes 30 fathers and 42 mothers as primary caregivers. This number is relatively like that which was used by Patra and Patro [15] in his study of the affiliate stigma in caregivers with autism.

There is a great amount of research showing that people with autism spectrum disorders (ASD) and people with ADHD are stigmatized and therefore discriminated against worldwide [16]. Stigma not only impacts autistic and ADHD children, but also extends to individuals who are close to them, particularly their parents. The current evaluation of affiliate stigma and associative stigma between caregivers shows that caregivers of both disorders have a significant high level of affiliate and associative stigmas than those with other 


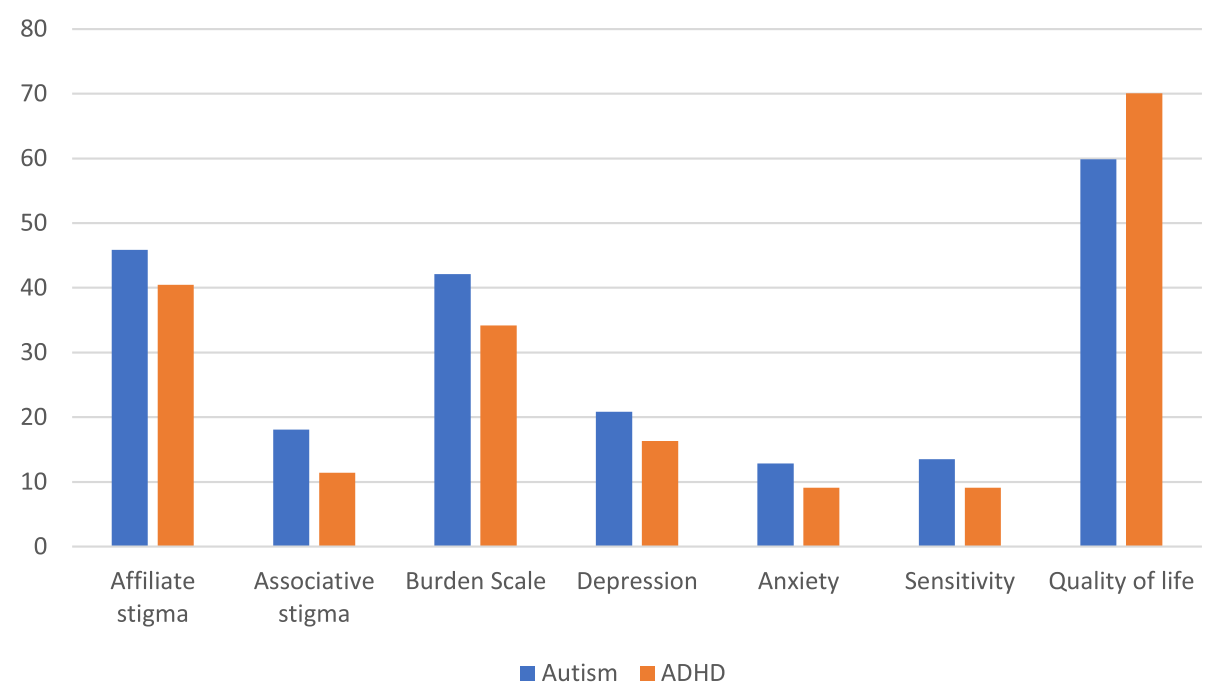

Fig. 1 Difference in affiliate stigma and associative stigma, burden scale, and anxiety, sensitivity, and quality of life between caregivers of autism and caregivers of ADHD

Table 3 Comparison of affiliate stigma and associative stigma, burden scale, and sensitivity, between father caregivers and mother caregivers of both disorders

\begin{tabular}{lllll}
\hline Variables & $\begin{array}{l}\text { Father } \\
\text { caregivers } \\
\text { Mean } \pm \text { SD }\end{array}$ & $\begin{array}{l}\text { Mother } \\
\text { caregivers } \\
\text { Mean } \pm \text { SD }\end{array}$ & $\boldsymbol{T}$ & $\boldsymbol{p}$ value \\
\hline Affiliate stigma & $40 \pm 9.22$ & $45.66 \pm 10.50$ & 2.42 & .018 \\
$\begin{array}{l}\text { Associative } \\
\text { stigma }\end{array}$ & $12.86 \pm 8.177$ & $16.40 \pm 6.43$ & 2.05 & .044 \\
Burden scale & $34.13 \pm 16.43$ & $41.40 \pm 12.63$ & 2.032 & .047 \\
Sensitivity & $1.04 \pm .64$ & $1.42 \pm .71$ & 2.31 & .024 \\
Quality of life & $64.466 \pm 13.20$ & $64.80 \pm 15.44$ & .099 & .922 \\
Depression & $1.382 \pm .683$ & $1.48 \pm 719$ & .592 & .937 \\
Anxiety & $1.063 \pm .621$ & $1.150 \pm .658$ & .563 & .735 \\
\hline$T$-test & & & &
\end{tabular}

disorders. Data that are like other several related studies [17-19] demonstrate the extent of stigma and disease burden on caregivers of autistic children with little concerns towards those with ADHD caregivers. The current results highlight the difference between the extent of stigma and disease burden caregivers of ASD children and those with ADHD.

The current results show that caregivers of autistic children have a higher level of stigma and burden than those with ADHD caregivers. Rearing a child with ASD is a great challenge for parents. These parents report greater stress and poorer mental health than the parents of children with other disabilities like ADHD $[20,21]$. Several results of previous research suggest that the experience of affiliate and associative stigma is prevalent and severe in caregivers of children with ASD [22].

Cadman et al. [4] focus on the increased recognition that both ASD and attention-deficit/hyperactivity disorder (ADHD) are associated with significant mental and emotional burdens to caregivers [5, 23]. Evaluation of caregiver's depressive, anxiety, and sensitivity symptoms shows that caregivers of autistic children have higher scores of depressions, anxiety, and sensitivity than those caregivers of ADHD children. Caregivers with intense affiliate stigma may agree with public stigma toward them at the cognitive level; feeling shame, embarrassment, and negative emotions stemming from internalized stigma at the affective level; and withdraw from social relations or alienate themselves from closely affiliated stigmatized family members or people at the behavioral level with higher levels of depression and anxiety [23]. This data is consistent with several other studies showing that caregivers of ASD and caregivers of ADHD have high prevalence of depression and anxiety [5, 24-26].

The high level of stigma and disease burden negatively impacts the psychological health of the caregiver parents of children with ASD or ADHD. This may lead to a marked deterioration regarding the quality of life of those caregivers. The current results explain that caregivers show that there is a significantly lower quality of life in caregivers of autism than those with ADHD. ASD and ADHD have an impact on the family unit, increasing family burden and decreasing family functioning and quality of life (QoL) of both the children and their parents [27-29]. 


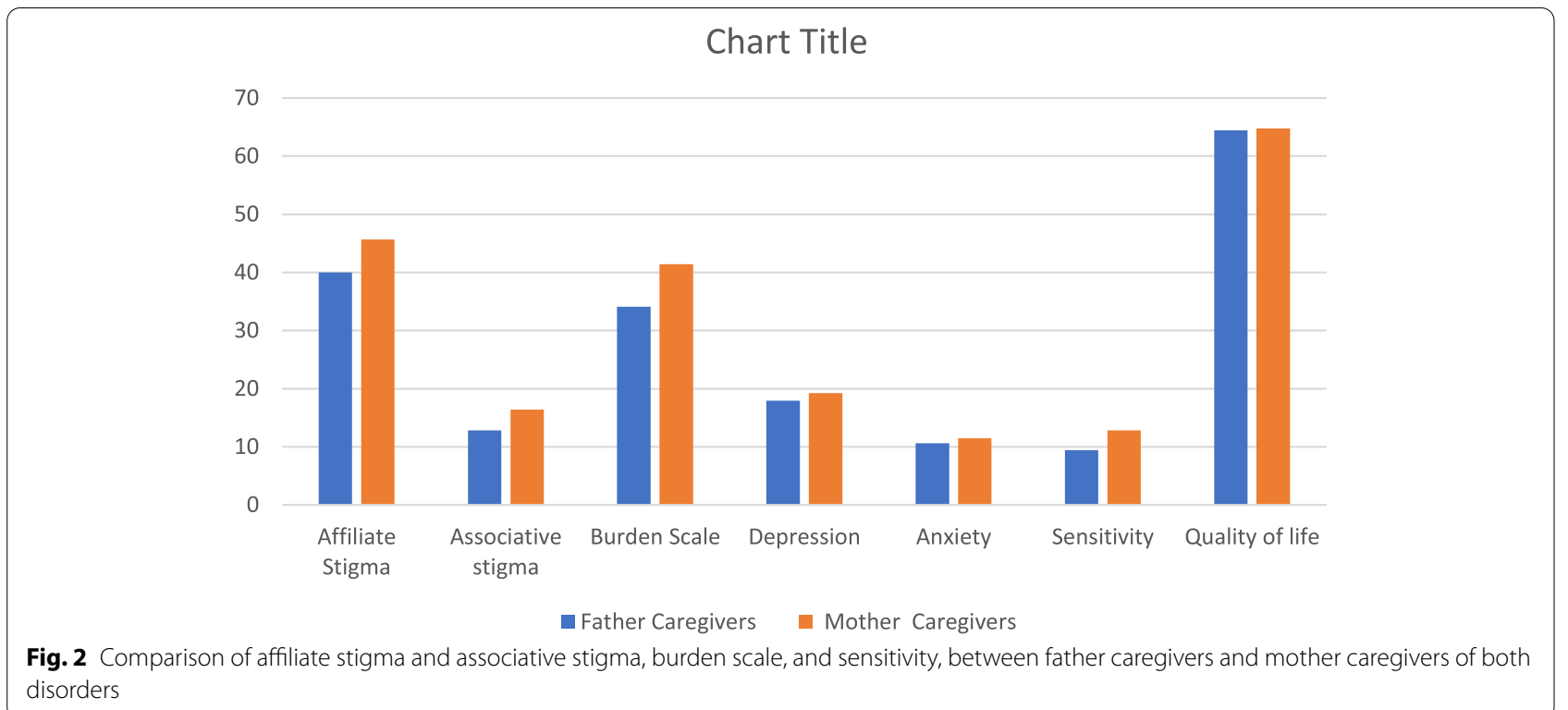

Table 4 Correlation between affiliate stigma and depression, anxiety, sensitivity, and quality of life in caregivers of ADHD and ASD children

\begin{tabular}{ll}
\hline Variables & Affiliate stigma \\
\hline Depression & $R=0.367(p=0.001)^{* *}$ \\
Anxiety & $R=0.369(p=0.001)^{* *}$ \\
Sensitivity & $R=0.515(p=0.001)^{* *}$ \\
Quality of life & $R=-0.386(p=0.001)^{* *}$
\end{tabular}

$R$ Pearson correlation

**Significant correlation $(p<0.01)$

World Health Organization, 2016, highlights that stigma adversely affects children and caregivers with autism spectrum disorder (ASD) and ADHD in different cultural contexts [30]. The current results examine the extent of how much stigma interferes with the mental health and QOL of the caregivers. Stigma has a statistically significant predictive power for the development of depression, anxiety, and sensitivity with negative impact for the QOL.

\section{Conclusions}

This study supports the notion that both ADHD and ASD pose a great challenge to their caregivers. Both caregivers have a higher score of affiliate, associative stigma, and diseases burden. Also, both caregivers have a higher score of depression, anxiety, and sensitivity than normal. Both caregivers have also a significantly lower quality of life. The study also examines the difference of severity of such variable between caregivers of ASD and ADHD showing that caregivers with ASD have a higher score of stigma, burden, depression, anxiety, and sensitivity than caregivers of ADHD. Also, they have a significantly lower QOL scores than caregivers of ADHD.

\section{Recommendations}

Management plans for children with ASD and ADHD should focus on the mental health of their caregivers and provide sufficient social support for those

Table 5 Results of a simple regression analysis of affiliate stigma in predicting depression, anxiety, sensitivity, and quality of life in caregivers of ADHD and ASD children

\begin{tabular}{llllllllll}
\hline Variables dependent & Predict variables & Constant & $\boldsymbol{R}$ & $\boldsymbol{R}^{\mathbf{2}}$ & $\boldsymbol{F}$ & $\boldsymbol{B}$ & Beta & $\boldsymbol{T}$ & Sig \\
\hline Affiliate stigma & Depression & .359 & .367 & .135 & 10.924 & .025 & .367 & 3.305 & .001 \\
& Anxiety & .122 & .369 & .136 & 11.018 & .023 & .369 & 3.319 & .001 \\
& Sensitivity & .261 & .515 & .265 & 25.263 & .035 & .515 & 5.026 & .000 \\
& Quality of life & 88.079 & .386 & .149 & 12.245 & .541 & .386 & 3.499 & .001 \\
\hline
\end{tabular}

Independent variables are depression, anxiety, sensitivity, and quality of life, while dependent variables are affiliate stigma

$A D H D$ attention-deficit hyperactivity disorder, $A S D$ autism spectrum disorder 
vulnerable caregivers in order to provide the best care for their affected children.

\section{Study limitation}

Although these results may be considered as a starting point for future studies focused on parents of children with ADHD and ASD, the present study has some limitations. First, the impact of the disease severity and clinical characteristics of the affected child should be considered and correlated with the study variable rather than the diagnosis itself. Second, the limited current resources interfere with the sample size that should be larger with multicentric study. Third, the study did not asses the socioeconomic status of such caregivers that may have a role in the extend of stigma and disease burden

\section{Abbreviations}

ASD: Autism spectrum disorder; ADHD: Attention-deficit hyperactivity disorder; SCL: Symptom checklist; SPSS: Statistical Package for Social Science; QOL: Quality of life; WHOQOL-BREF: The World Health Organization Quality of LifeBREF; EMIC-CSS: Explanatory Model Interview Catalogue- Community Stigma Scale; ZBI: The Arabic version of the Zarit Burden Interview.

\section{Acknowledgements}

Not applicable.

\section{Authors' contributions}

R. H. contributed to the study design, interpretation of the data, and preparing and revising the manuscript; also, he is the corresponding author. D.H. contributed to the study design, assessing, interviewing the patients, collecting, and analyzing and interpreting the data. All authors have read and approved the final manuscript.

\section{Funding}

The current study was not supported by any national or international institution or organization.

\section{Availability of data and materials}

The datasets generated and/or analyzed during the current study are available from the corresponding author on reasonable request.

\section{Declarations}

\section{Ethics approval and consent to participate}

All procedures performed in studies involving human participants were in accordance with the ethical standards of the institutional and/or national research committee and with the 1964 Helsinki Declaration and its later amendments or comparable ethical standards. The current study was also approved by Faculty of Medicine, Assiut University Ethical Committee (Reference number is not available). Informed consent was obtained from all individual participants included in the study.

\section{Consent for publication}

All authors consent to the publication of the manuscript.

\section{Competing interests}

Authors declare that they have no competing interests.

\section{Author details}

${ }^{1}$ Department of Neurology and Psychiatry, Faculty of Medicine, Assiut University, Assiut, Egypt. ${ }^{2}$ Faculty of Arts, Assiut University, Assiut, Egypt.
Received: 13 September 2021 Accepted: 3 November 2021

Published online: 28 December 2021

\section{References}

1. American Psychiatric Association (2013) Diagnostic and Statistical Manual of Mental Disorders, Fifth Edition (DSM-5). American Psychiatric Publishing, Arlington, VA

2. Fridman M, Banaschewski T, Sikirica V, Quintero J, Chen KS (2017) Access to diagnosis, treatment, and supportive services among pharmacotherapy-treated children/adolescents with ADHD in Europe: data from the Caregiver Perspective on Pediatric ADHD survey. Neuropsychiatr Dis Treat 13:947-958. https://doi.org/10.2147/ndt.s128752. PMID: 28408828; PMCID: PMC5384740

3. Attention deficit hyperactivity disorder: diagnosis and management NICE guideline [NG87] Published: 14 March 2018 Last updated: 13 September 2019Available from: https://www.nice.org.uk/guidance/cg72. Accessed July 21, 2016

4. Cadman T, Spain D, Johnston P, Russell A, Mataix-Cols D, Craig M, Deeley Q, Robertson D et al (2015) Obsessive-Compulsive Disorder in Adults with High-Functioning Autism Spectrum Disorder: What Does Self-Report with the OCI-R Tell Us?. Autism Res 8:477-485

5. Cadman T, Eklund H, Howley D (2012) Caregiver burden as people with ASD and ADHD 'transition' into adolescence and adulthood. J Am Acad Child Adolesc Psychiatry 51:879-888

6. Mak WWS, Cheung RYM (2008) Affiliate stigma among caregivers of people with intellectual disability or mental illness. J Appl Res Intellect Disabil 21:532-545

7. Corrigan PW, Watson AC (2002) The paradox of self-stigma and mental illness. Clin Psychol Sci Pract 9:35-53

8. Broady TR, Stoyles GJ, Morse C (2017) Understanding carers' lived experience of stigma: the voice of families with a child on the autism spectrum. Health Soc Care Commun 25(1):224-233

9. Lee P, Lin K, Robson D, Yang H, Chen VC, Niew W (2013) Parent-child interaction of mothers with depression and their children with ADHD. Res Dev Disabil 34(January (1))

10. Bachner YG (2013) Preliminary assessment of the psychometric properties of the abridged Arabic version of the Zarit Burden Interview among caregivers of cancer patients. Eur J Oncol Nurs 17:657-660

11. Zarit SH, Reever KE, Bach-Peterson J (1980) Relatives of the impaired elderly: correlates of feelings of burden. The Gerontologist 20:649-655

12. Weiss M (1997) Explanatory Model Interview Catalogue (EMIC): Framework for comparative study of illness. Transcultural Psychiatry 34:235-263

13. Derogatis LR (1983) SCL-90-R: Administration, scoring and procedures. In: Manual II for the R (evised) Version and Other Instruments of the Psychopathology Rating Scale Series

14. Skevington SM, Lotfy M, O'Connell KA (2004) The World Health Organization's WHOQOL-BREF quality of life assessment: psychometric properties and results of the international field trial. A report from the WHOQOL group. Qual Life Res 13:299-310

15. Patra S, Patro BK (2019) Affiliate stigma among parents of children with autism in eastern India. Asian J Psychiatr 44:45-47

16. Recioa P, Moleroa F, García-Aela C, Pérez-Garínb D (2020) Perceived discrimination and self-esteem among family caregivers of children with autism spectrum disorders (ASD) and children with intellectual disabilities (ID) in Spain: The mediational role of affiliate stigma and social support. Res Dev Disabil 105:103737

17. Mitter N, Ali A, Scior K (2019) Stigma experienced by families of individuals with intellectual disabilities and autism: a systematic review. Res Dev Disabil 89:10-21

18. Mitter N, Ali A, Scior K (2018) Stigma experienced by family members of people with intellectual and developmental disabilities: multidimensional construct. BMJ Open 4:332-338

19. Klassen AF, Lee SK, Chan H (2002) Relationship between behavioral problems in children, caregiver burden and health-related quality of life: a NICU follow-up study. Qual Life Res 11(7):684

20. Ingersoll B, Hambrick DZ (2011) The relationship between the broader autism phenotype, child severity, and stress and depression in parents of children with autism spectrum disorders. Res Autism Spectr Disord 5:337-344 
21. Ault S, Breitenstein SM, Tucker S, Havercamp SM, Ford JL (2021) Caregivers of children with autism spectrum disorder in rural areas: a literature review of mental health and social support. J Pediatr Nurs 61:229-239

22. Wang, X., 1993. Assessments of mental health. Publishing House of Chinese Journal of Mental Health, Beijing, China.

23. Chena Y-L, Changc C-C, Chene Y-M, Liue T-L, Hsiaofg RC, Chouh W-J, Yen C-F (2021) Association between affiliate stigma and depression and its moderators in caregivers of children with attention-deficit/hyperactivity disorder. J Affect Disord 279:59-65

24. Yirmiya N, Shaked M (2005) Psychiatric disorders in parents of children with autism: a meta-analysis. J Child Psychol Psychiatry 46:69-83

25. Lecavalier L, Leone S, Wiltz $L$ (2006) The impact of behavior problems on caregiver stress in young people with autism spectrum disorders. J Intellect Disabil Res 50:172-183

26. Almansour MA, Alateeq MA, Alzahrani MK, Algeffari MA, Alhomaidan HT (2013) Depression and anxiety among parents and caregivers of autistic spectral disorder children. Neurosciences 18(1):58-63
27. Andrade EM, Geha LM, Duran P, Suwwan R, Machado F, do RosárioMC. (2016) Quality of life in caregivers of ADHD children and diabetespatients. Front. Psychiatry. 7(July)

28. Craig F, Operto FF, De Giacomo A, Margari L, Frolli A, Conson M et al (2016) Parenting stress among parents of children with neurode-velopmental disorders. Psychistry Res (August):242.7

29. Dey M, Castro RP, Haug S, Schaub MP (2019) Quality of life of parentsof mentally-ill children: a systematic review and meta-analysis. Epidemiol Psychiatr Sci 28(October (5))

30. Mayada et al (2012) Global prevalence of autism and other pervasive developmental disorders. Autism Res 5(3):160-179

\section{Publisher's Note}

Springer Nature remains neutral with regard to jurisdictional claims in published maps and institutional affiliations.

\section{Submit your manuscript to a SpringerOpen ${ }^{\circ}$ journal and benefit from:}

- Convenient online submission

- Rigorous peer review

- Open access: articles freely available online

- High visibility within the field

- Retaining the copyright to your article

Submit your next manuscript at springeropen.com 